\title{
Determination of the Focal Mechanisms of Events in Brazil Central
}

\author{
Juraci Carvalho ${ }^{1}$, Lucas Barros ${ }^{1}$, Darlan Portela Fontenele ${ }^{1}$.
}

1- Seismological Observatory of the University of Brasilia, Brasília - DF - Brazil

Copyright 2016, SBGf - Sociedade Brasileira de Geofísica

Este texto foi preparado para a apresentação no VII Simpósio Brasileiro de Geofísica Ouro Preto, 25 a 27 de outubro de 2016. Seu conteúdo foi revisado pelo Comitê Técnico do VII SimBGf, mas não necessariamente representa a opinião da SBGf ou de seus associados. É proibida a reprodução total ou parcial deste material para propósitos comerciais sem prévia autorização da SBGf.

\begin{abstract}
In this paper we present the results of the Focal Mechanisms (FM) determination for four weak events from the Goiás-Tocantins Seismic Zone (GTSZ) using the method of Cyclic Scanning of the Polarity Solutions (CSPS), such method makes use of the full waveform inversion to constrain the non-unique focal mechanism solutions, obtained by the FOCMEC program, from a set of few available polarities only. The solution reliability is controlled by a series of quality control parameters. The events occurred in the Brazil Central region, close to the cities of Mara Rosa/GO (2010), Formoso/GO (2011), Aliança/TO (2011) and Peixe/TO (2015).
\end{abstract}

\section{Introduction}

Knowledge of the distribution of crustal efforts is critical for the understanding of tectonics and seismicity, particularly in the intraplate regions (Zoback, 1992). The vast majority of field stress estimates on a global scale was determined using earthquake focal mechanisms (Heidbach et al., 2004). In Brazil, only a few focal mechanisms of earthquakes were obtained due to the low seismicity and the shortage of seismographic stations, so little is known about the state of stress in the Brazilian intraplate.

In this paper we focus on the relocation and determination of moment-tensor for four events occurred in the Brazil Central, more precisely in the seismic zone GoiásTocantins (SZGT), inserted in the geological contest of the Tocantins Province, which includes, among others, the great geological structure named Transbrasiliano Lineament (TBL). The region is characterized by seismic events of low magnitude $(M<3.5)$ distributed in a seismic strip parallel to TBL but not coincident (Fig. 1). Most of the events were recorded by stations of the Brazilian Seismograph Network (RSBR), seismographic Network SIS-UnB (OS) and BDFB station belonging to the global network (GT). The events in the region are too weak to have their focal mechanisms (MF) obtained by the traditional method of using only $\mathrm{P}$ phase polarities. To overcome this limitation in solving the moment tensor, for some events, we used the methodology implemented in ISOLA program (Sokos \& Zahradnik 2008; 2013) jointly with the CSPS tool (Cyclic Scanning of the Polarity
Solutions), which makes use of the inversion of the complete waveforms for a small group of solutions previously obtained by phase polarities method, using only few available polarities (Snoke et al., 1984).

\section{Area of Study}

The seismic events of the SZGT are distributed in a seismic strip of about $200 \mathrm{~km}$ wide and $700 \mathrm{~km}$ long oriented to the direction NE-SW (Fig. 1). The seismic zone is located at the central Brazil and distributed over the states of Goiás, Tocantins and part of Mato Grosso, extending from the northwest of the Paraná Basin to the southwest of the Parnaiba Basin. The geophysical expression is mainly characterized by a high gravity anomaly along the folding track Tocantins Araguaia (Assumpção et al., 1986; Fernandes et al., 1991). The Transbrasiliano Lineament consists of a set of geological structures formed in the Neoproterozoic, with the convergence of the São Francisco Craton and the Amazonian Craton, during the formation of the eastern part of the supercontinent Gondwana.

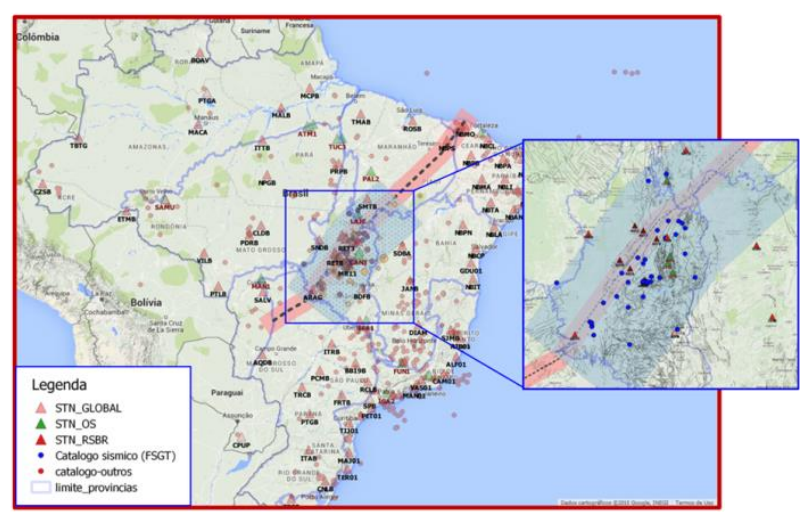

Figure 1 - Epicentral map of the Goiás Tocantins Seismic Zone (range in transparent blue) and Transbrasiliano lineament structures, black lines with preferential distribution NE-SW (dashed line with pink shading). The highlighted rectangle shows the study area with the selected events (blue circles). Brazilian Seismograph Network (RSBR) red triangles and the SIS-UnB Seismograph network (OS) green triangles.

\section{Methodology}

In this work we will use the Standard ISOLA (SI) software (Sokos \& Zahradnik 2008; 2013) for the waveform inversion and the CSPS - Cyclic Scanning of the Polarity Solutions (Fojtiková \& Zahradnik 2014). The ISOLA software is based on the least-squares calculation of the moment tensor and a grid search of the centroid position 
and time. A single point-source approximation is used, and the moment-rate time dependence is assumed to be known. The software uses the complete displacement waveforms (without pre-selecting any phases); and the time domain inversion. The Earth response is represented by the Green's functions calculated in a 1D velocity model, and using the discrete- wavenumber method. The ISOLA also computes several parameters to allow the calculated solution quality assessment.

The CSPS is a combination of the standard waveform inversion constrained by the focal mechanisms with the use of the first P-phase polarity, calculated by the FOCMEC. For each group of focal mechanism, this technique yields a set of solutions with the well-adjusted waveforms (synthetic and observed). At a favorable context (good signal-to-noise ratio, well recorded events, many stations, etc.), this approach makes possible the determination of the focal mechanism with few polarities $(\sim 10)$ and few well recorded waveforms ( 4). The FOCMEC makes a grid search over strike dip and rake to find the focal mechanisms satisfying the polarities of the seismic signals. Here we will present the data processing of the event number 2 of the table 1.

Table 1 - Events used in the inversion to obtain the focal mechanism.

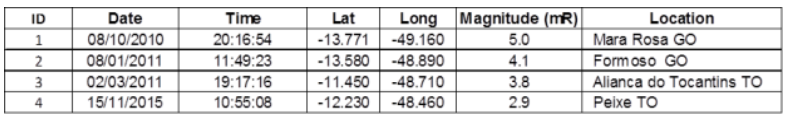

\section{Data processing}

Standard ISOLA: The Formoso event inversion (number 2 in the above table) was done using three stations at distances of MR08 (30 km), MR07 (37 km) and CAN3 (84 $\mathrm{km}$ ). The velocity model used was Lucas_GT5 (Barros et al., 2015) and the processing quality control showed a large uncertainty, see the nodal plane dispersion in Figure 2 (Up right), $V R=0.61$ and $\mathrm{CN}=16.3$, mainly due to the stations distances and a non-favorable distribution of the stations. The polarity check showed one misfit.

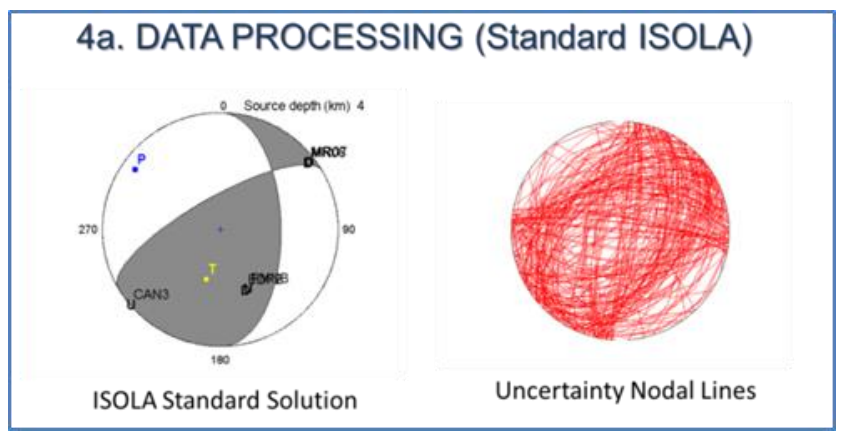

Figure 2 - Formoso event inversion results using the ISOLA program standard version. Left is the best solution and right shows the nodal plane uncertainty.
The obtained best solution NP1 was 234/63/125 and NP2 was 357/43/42 (strike/dip/rake), Figure 3. The centroid position and depth, magnitude and time are in agreement with the event source parameters.

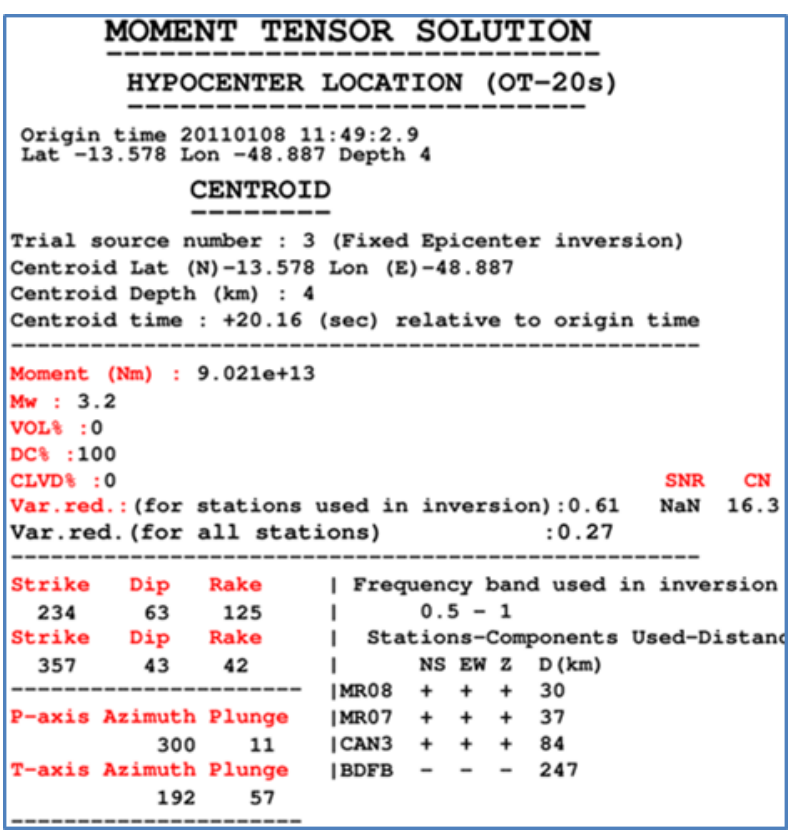

Figure 3 - Results from the inversion of Formoso event using standard ISOLA and waveforms from three stations, MRO8, MRO7 and CAN3.

Cyclic Scanning of the Polarity Solutions: The CSPS technique makes use of the Formoso event nodal planes calculated by the FOCMEC program, Figure 4 left (large dispersion), and constrain the NP solutions using the wave form inversion to find the best solutions that suits the waveform adjustment (synthetic and observed), the result Figure 4 right.

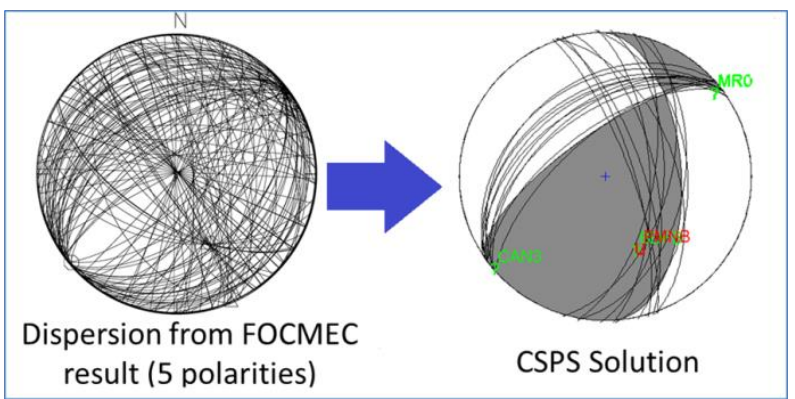

Figure 4 - Results from the CSPS process, left are the nodal plane solutions from the FOCMEC program using only $5 P$ polarities (high dispersion). Right are the nodal plane solutions constrained by the ISOLA waveform inversion. 


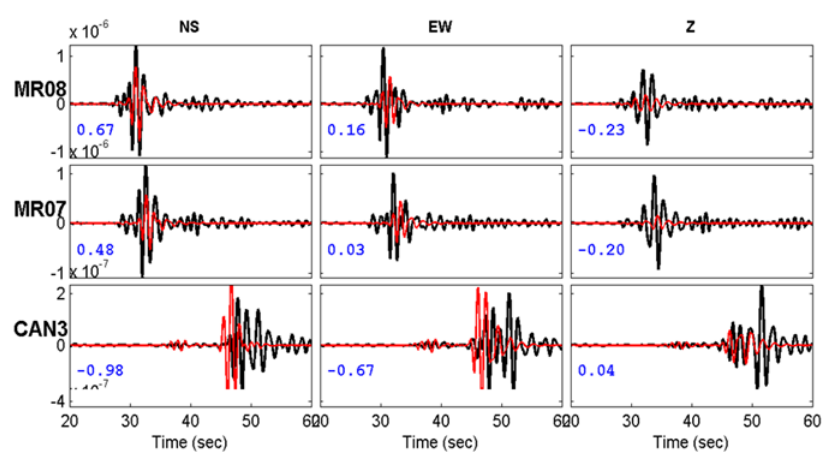

Figure 5 -Seismograms from the Formoso event recorded at the stations MR08, MR07 and CAN3 and with best obtained adjustment of synthetic (red) and observed (black). The waveforms were filtered at a frequency band of 0.5 to $1.0 \mathrm{~Hz}$.

\section{Results}

The focal mechanisms (Fig. 6) obtained from the processing of the four events showed to be consistent with previous studies with the $\mathrm{P}$ and $\mathrm{T}$ axis in concordance with the regional stress NW-SE() (Assumpção et al., 2014; Carvalho et al., 2014 and Agurto-Detzel et al., 2014).

Table 2 - Results of S/D/R NP1 and NP2 and the $P$ and T axis (Azimuth and Plunge).

\begin{tabular}{|l|c|c|c|c|}
\hline & $\begin{array}{c}\text { NP1 } \\
(\mathrm{S} / \mathrm{D} / \mathrm{R})\end{array}$ & $\begin{array}{c}\mathrm{NP2} \\
(\mathrm{S} / \mathrm{D} / \mathrm{R})\end{array}$ & $\begin{array}{c}\text { P-axis } \\
\text { (Azim/Plunge) }\end{array}$ & $\begin{array}{c}\text { T-axis } \\
\text { (Azim/Plunge) }\end{array}$ \\
\hline Mara Rosa (2010) & $216 / 49 / 74$ & $60 / 43 / 108$ & $317 / 3$ & $60 / 78$ \\
\hline Formoso (2011) & $234 / 63 / 125$ & $357 / 43 / 42$ & $300 / 11$ & $192 / 57$ \\
\hline Aliança (2011) & $195 / 53 / 92$ & $12 / 37 / 87$ & $284 / 8$ & $115 / 82$ \\
\hline Peixe (2015) & $194 / 71 / 109$ & $327 / 26 / 46$ & $269 / 24$ & $130 / 59$ \\
\hline
\end{tabular}
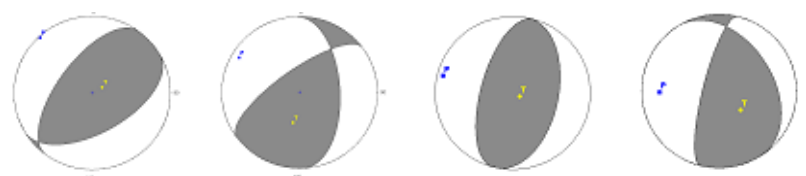

Figure 6 - Beachball showing from left to right the Nodal planes solutions and P\&T axis for the events of Mara Rosa (2010), Formoso (2011), Aliança (2011) and Peixe (2015).

\section{Discussion and Conclusions}

Small events recorded by a sparse seismograph network are challenging to determine reliable source parameters. To overcome the difficulties, it requires a careful data processing and the application of several (complementary) techniques. It is also very important to assess uncertainties of the source parameters.

Here we assume that the events are tectonic hence we expect a high percentage of double couple. Low percentage indicates rather problematic solutions.
The group of events situated in the SZGT is distributed in a NE-SW strip; in this sense they might be linked to some dominant effect, like a structure, geology and stresses orientation.

The preliminary results for the event of Trombas/Formoso-GO showed a relatively good waveform fit (variance reduction 0.6). However, it provided a very large uncertainty of the focal-mechanism nodal lines and the double-couple percentage (the latter having predominantly low values, < 50). Such a poor resolvability is related to the large condition umber (16), reflecting unfavorable distribution of the three used stations.

For the processing we used two different bandwidths for the two nearby stations (MR08 and MR07), which helped to avoid overweighting due to proximity of the two stations.

The focal-mechanism inversion based on the same three stations, but pre-constrained in CSPS method by five polarities [processed in FOCMEC allowing one polarity misfit] provided similar optimal strike/dip/rake angles as the standard ISOLA, i.e., 234/63/125 (NP1) and 357/43/42 (NP2) and magnitude of $3.2 \mathrm{Mw}$. The depth (4$5 \mathrm{~km}$ ) showed to be stable. The combined use of polarities and waveforms, together with an implicit assumption of $100 \%$ double-couple in the CSPS method, likely increase reliability of the solution.

A better resolved solution can be expected for events of comparable (or larger magnitude) if they are recorded by at least one more relatively near station, reducing the present (180 degrees) azimuthal gap. Future focal mechanism studies of weak events are most promising for aftershock series recorded by a temporary seismic network.

Despite of the difficulty to obtain focal mechanisms of weak events, the applied technique used to determine the moment tensor for the weak events (four), we obtained good results, consistent with previous studies (Barros at all., 2015; Carvalho et all., 2015 and Zahradinik et all., 2015).

\section{References}

Agurto-Detzel, H. et al., 2014. The 2012-2013 Montes Claros earthquake series in the Sao Francisco Craton, Brazil: new evidence for non-uniform intraplate stresses in mid-plate South America. Geophysical Journal International, 200(1), pp.216-226. Available at: http://gji.oxfordjournals.org/content/200/1/216 [Accessed December 15, 2014].

Assumpção, M. et al., 2014. Intraplate Seismicity in Brazil. In Intraplate Earthquakes,. In Cambridge U.P, ed. Talwani, $\mathrm{P}$.

Assumpção, M., Lima, T.M. \& Tomás, L.A., 1986. O sismo de Araguapaz de 14.01.1986 e o Lineamento Transbrasiliano. In 340 Congresso Brasileiro de Geologia, Goiânia. p. 5p. 
Barros, L. V. et al., 2015. The Mara Rosa 2010 GT-5 earthquake and its possible relationship with the continental-scale Transbrasiliano Lineament. Journal of South American Earth Sciences, 60, pp.1-9. Available at: http://linkinghub.elsevier.com/retrieve/pii/S089598111500 0280.

Carvalho, J.M., Barros, L. V. \& Zahradník J., 2014. Seismic source parameters of local micro-earthquakes in Goiás State Brazil by waveform inversion (abstract),. Earth Sci. Res. J. 18, special issue,, pp.166-167.

Fernandes, E.P., Blum, M.L.A. \& Ribeiro, R., 1991. The Goiás seismic zone, a new approach. In Extended Abstract. $35^{\circ}$ Congress Braz. Geol. Soc., Salvador/BA. pp. 553-558.

Fojtiková, L. \& Zahradnik, J., 2014. A New Strategy for Weak Events in Sparse Networks: The First-Motion Polarity Solutions Constrained by Single-Station Waveform Inversion. Seismological Research Letters, 85(6), pp.1265-1274. Available at: http://srl.geoscienceworld.org/cgi/doi/10.1785/022014007 2 [Accessed November 27, 2014].

Heidbach, O. et al., 2004. Stress maps in a minute: The 2004 world stress map release. Eos, Transactions American Geophysical Union, 85(49), p.521. Available at: http://doi.wiley.com/10.1029/2004EO490001 [Accessed December 15, 2014].

Snoke, J.A. et al., 1984. A program for focal mechanism determination by combined use of polarity and SV-P amplitude ratio data,. , pp.1-15.

Sokos, E. \& Zahradnik, J., 2013. Evaluating CentroidMoment-Tensor Uncertainty in the New Version of ISOLA Software. Seismological Research Letters, 84(4), pp.656665. Available at:

http://srl.geoscienceworld.org/cgi/doi/10.1785/022013000 2 [Accessed December 23, 2014].

Sokos, E.N. \& Zahradnik, J., 2008. ISOLA a Fortran code and a Matlab GUI to perform multiple-point source inversion of seismic data. Computers \& Geosciences, 34(8), pp.967-977. Available at: http://linkinghub.elsevier.com/retrieve/pii/S009830040800 0277 [Accessed December 23, 2014]. 